\title{
Trends in amphetamine and benzodiazepine use among drivers arrested for drug impaired driving in Norway 2000-2009
}

\author{
Stig Tore Bogstrand ${ }^{1,2}$, Gerrit Middelkoop ${ }^{1}$ and Asbjørg S. Christophersen ${ }^{1}$ \\ 1) Norwegian Institute of Public Health, Division of Forensic Toxicology and Drug Abuse, PO Box 4404 Nydalen, N- \\ 0403 Oslo, Norway \\ 2) Oslo University Hospital, Division of Critical Care, Department of Research and Development, N-0407 Oslo, Norway \\ Correspondence: Stig Tore Bogstrand, Norwegian Institute of Public Health, Division of Forensic Toxicology and Drug Abuse, \\ PO Box 4404 Nydalen, N-0403 Oslo, Norway \\ E-mail: StigTore.Bogstrand@fhi.no Telephone: +4721077822
}

\begin{abstract}
The patterns of drug use among drivers suspected for driving under the influence of non-alcohol drugs have changed over the past ten years. The aim of this study was to describe trends in single substance prevalence and total prevalence of benzodiazepines and amphetamines in blood samples from apprehended drivers, and compare findings with statistics of drug seizure by year. The sample represented totally 39935 apprehended drivers, varying from about 3500 to 4800 each year between 2000 and 2009. The study found that after 2002 the prevalence of benzodiazepine has ranged from 52 to $57 \%$ among all apprehended drivers. There have been major changes in single substance prevalence, and the changes are similar to the changes in benzodiazepine seized by the police. There was no significant changes in the prevalence of amphetamines from 2000 to 2009 (35-43\%), but the most prevalent stimulant has shifted from amphetamine to methamphetamine in both police seizures and blood samples from apprehended drivers. A combination of benzodiazepines and amphetamines was commonly detected in samples from apprehended drivers.
\end{abstract}

\section{INTRODUCTION}

Characteristics of drivers apprehended by the police for driving under the influence (DUI) of alcohol or other psychoactive substances have been described earlier in several studies (1-5). Based on information from police protocols the main reasons for apprehension are accidents, reckless or dangerous driving (1). The typical apprehended driver is a man between 20 and 35 years of age. He usually combines several psychoactive substances; illegal, medicinal drugs and alcohol. The blood concentrations of the medicinal psychoactive drugs are usually higher than expected from recommended therapeutic doses (2). Re-arrest rates are higher for drivers arrested for drugged driving compared to those arrested for drunk driving (1). The apprehended drivers run a high risk of early death compared to the general population $(1,6)$, and problem drug users are probably overrepresented among apprehended drivers. A comparison of sale statistics of prescribed benzodiazepine use recorded in the prescription register and use among apprehended drivers showed different age distributions for the two groups. The majority of the apprehended drivers with benzodiazepine detected were between 20 and 40 years old, while the majority of prescription users were older than 50 years of age (3). Police statistics over the last ten years shows a marked downturn in the seizures of the benzodiazepine flunitrazepam while the seizures of clonazepam have increased. In the same period of time the proportion of methamphetamine in the total number of amphetamine and methamphetamine seizures have increased from $1.8 \%$ in 2000 to $64.3 \%$ in 2009 (7).
The aim of this study was to:

- Report the prevalence of amphetamine and methamphetamine and benzodiazepines in blood samples from apprehended drivers by year. Hypothesis: prevalence rates of benzodiazepines and amphetamines are stable, while single substances changes from year to year.

- Compare police seizure statistics with prevalence of benzodiazepines and amphetamines in apprehended drivers. Hypothesis: changes in police seizures are reflected in the analytical results of blood samples from apprehended drivers.

\section{METHODS}

\section{Participants}

The drivers included in the sample material were stopped by the Norwegian police on the suspicion of impaired driving in Norway from 2000 to 2009. The driver may have been involved in an accident, stopped for dangerous or reckless driving, reported to the police, or stopped in a roadside control. The suspected driver was transported to a police physician for blood sampling and clinical examination in case of drug suspicion. Samples were sent to the Norwegian Institute of Public Health (NIPH), Division of Forensic Medicine and Drug Abuse, for drug analysis if the police suspected use of psychoactive non-alcohol drugs. The blood samples were analysed for about 25 different drugs and alcohol. A more detailed description of the procedure has been published earlier $(4,5)$. 
An anonymous dataset comprising year of analysis, amphetamine and benzodiazepine findings for all cases suspected of driving under the influence of alcohol or other psychoactive substances in the database from 2000-2009 were extracted from the database at the institute.

\section{Variables}

The "amphetamines" variable consists of all drivers submitting a blood sample which was found to be positive for amphetamine or methamphetamine. Samples being positive for ecstasy (MDMA) and similar compounds only, were not included. "Amphetamine" samples consisted of drivers who submitted blood samples found to be positive for amphetamine without considering whether methamphetamine was present or not. "Amphetamine -no meth finding" consists of drivers who submitted blood samples that were positive for amphetamine only and negative for methampethamine. About seven percent methamphetamine is metabolized to amphetamine in the body; as described in figure 1 . Ingestion of methamphetamine may therefore lead to a sample positive for both methamphetamine and amphetamine (8). No amphetamine to methamphetamine ratio was calculated, and no attempt was made to examine whether a positive finding of amphetamine and methamphetamine was from methamphetamine use alone or combined use. The variable "methamphetamine" includes all cases positive for methamphetamine, with no regard to the amphetamine result.

Flunitrazepam, clonazepam, alprazolam, diazepam, oxazepam and nitrazepam were included in the category benzodiazepines. Positive samples were reported independently as single substances and together as benzodiazepines. Combinations of benzodiazepines were also counted.

The seizure statistic presented in figure 2 and 3 was from the publication "Narkotika og Dopingstatistikk 2010" published by the police (7). Calculation of proportions of methamphetamine in figure 2 was proportion in the total amount of seized amphetamine and methamphetamine and not proportions of the total amount of all seized drugs (7). To make better comparisons, the seizure statistic was therefore compared with methamphetamine positive drivers within drivers positive for amphetamine and methamphetamine. The same comparisons were performed for benzodiazepines: one benzodiazepine type as the proportion of all benzodiazepines seized was compared to one benzodiazepine type blood sample finding as proportion of all benzodiazepine findings by year.

\section{Data sources}

The blood sample analysis was performed at NIPH in Oslo, Norway. According to forensic guidelines all positive samples were analyzed twice with both screening and confirmation/quantization methods. During the study period there have been some minor changes in analytical methods and cut-off changes for some compounds.

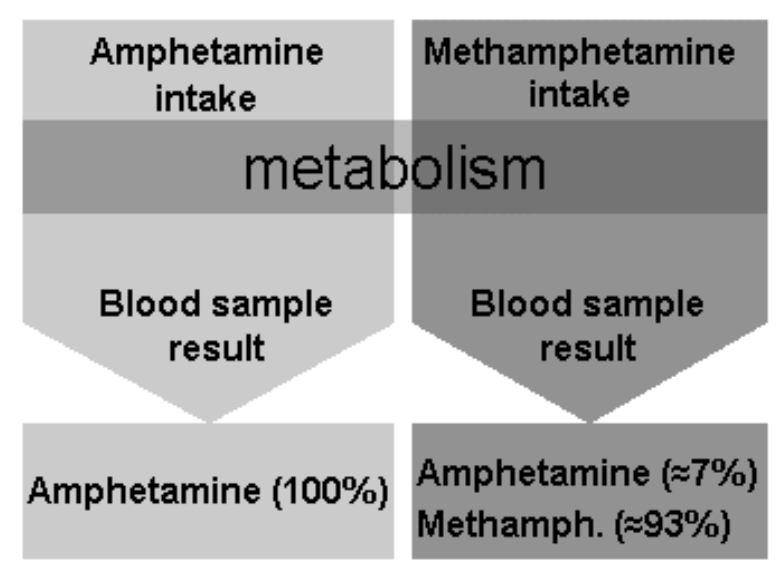

Figure 1. Amphetamine and methamphetamine metabolism.

\section{Benzodiazepines}

From 2000 until June 2001 a gas chromatography with electron capture detector (GC-EC) method, from June 2001 until May 2009 a high-performance liquid chromatography mass spectroscopy (HPLC-MS) $(4,9)$ method and after May 2009 an ultra-performance liquid chromatography mass spectroscopy (UP-LC MSMS) method was used for screening blood samples for benzodiazepines (10). From 2000 until June 2001 a gas chromatography with electron capture detector (GC-EC) method (all except for oxazepam) and a liquid chromatography with UV detector (LC-UV) (oxazepam), from June 2001 until July 2007 a highperformance liquid chromatography mass spectroscopy (HPLC-MS) (4,9) method, and after July 2007 an ultra-performance liquid chromatography mass spectroscopy (UP-LC MSMS) method was used for confirmation and quantization of benzodiazepines. Cut-offs for all benzodiazepines were reduced in June 2001.

\section{Amphetamines}

From 2000 until May 2009 an immunological screening (11) and after May 2009 an ultra-performance liquid chromatography mass spectroscopy (UP-LC MSMS) method was used for screening blood samples for amphetamines (10). During the whole period a gas chromatography- mass spectroscopy (GC-MS) method was used for confirmation and quantization of both amphetamine and methamphetamine. Cut-offs for these compounds have not been changed during this period (12).

\section{Statistical methods}

Prevalence of psychoactive substances by year was analyzed with logistic regression to test if the trend was statistically significant. The trend was presented as odds ratios (OR) with $95 \%$ confidence intervals (CI). Limit of statistical significance was $p \leq 0.05$.

\section{Ethics}

All the data in this study was derived from an existing database at NIPH Division of Forensic Toxicology and Drug Abuse. All data was handled anonymously. 

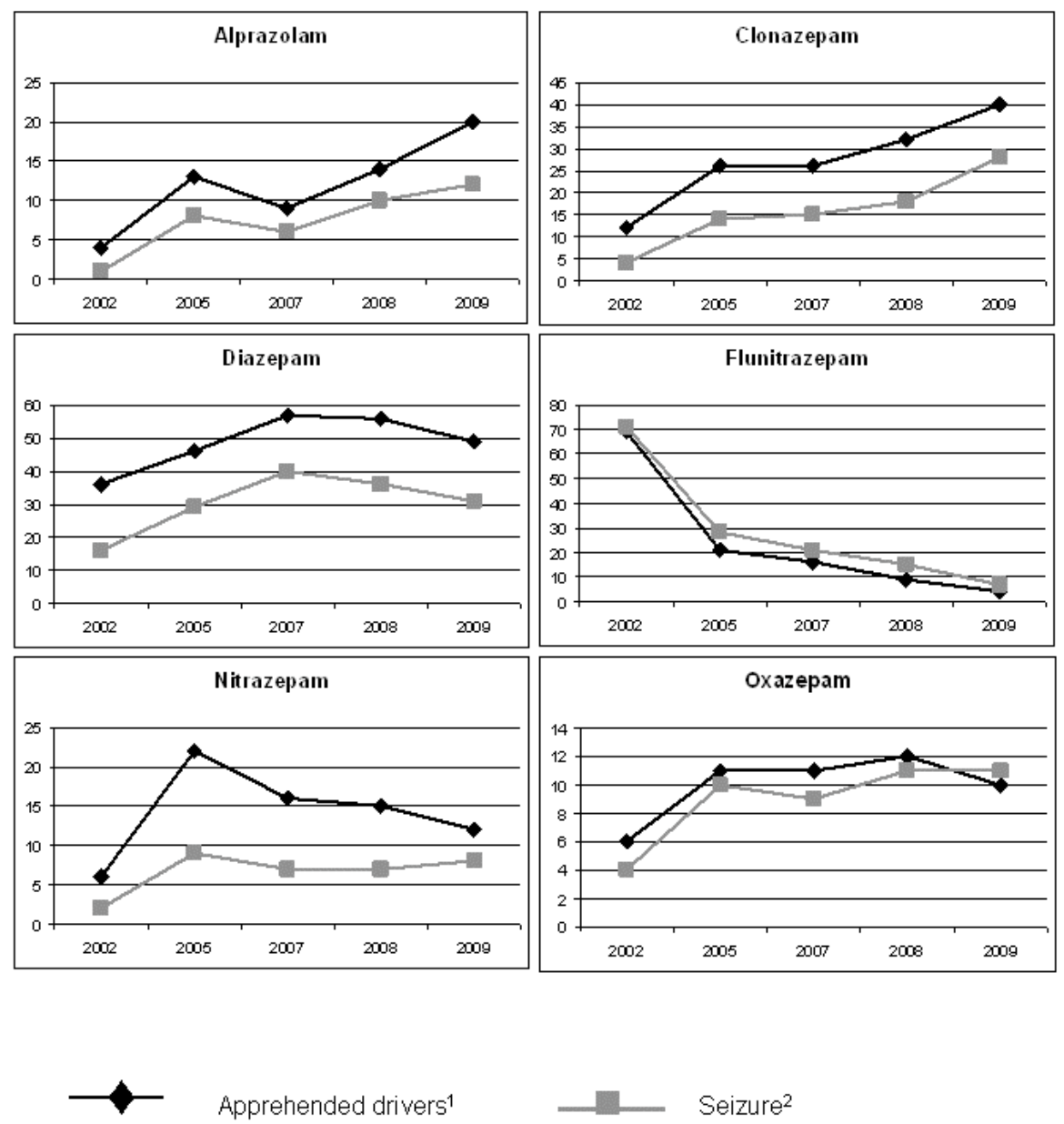

Figure 2. Prevalence of types of benzodiazepines compared to police seizures by year (Data from police seizures derives from Drugs and doping statistics 2010 (7)).

${ }^{1}$ Proportion of benzodiazepine type among drivers screening positive for benzodiazepines

${ }^{2}$ Proportion of benzodiazepine type in Police seizure of all benzodiazepines

\section{RESUlTS}

\section{Participants}

During the period 2000-2009, 39935 samples from drivers apprehended by the police were received at NIPH for analyses. All analytical results were included in the dataset. The highest number of samples was received in $2002(\mathrm{n}=4812)$, while the lowest number of samples was received in $2000(n=3507)$. No data other than the year and substance findings were derived from the database and analysed.

\section{Prevalence of amphetamines}

The total prevalence of amphetamines had not changed significantly during the ten year period. Prevalence rates varied between 35 and $43 \%$ for all samples analyzed. The type of stimulant used had, however, changed during the same period. Methamphetamine was detected in only $3 \%(n=109)$ of the samples from apprehended drivers in 2000, in 2009 methamphetamine was found in $35 \%(\mathrm{n}=1484)$ of the samples. Amphetamine alone was detected in $5 \%(\mathrm{n}=211)$ of the samples in 2009 (Table 1).

\section{Prevalence of benzodiazepines}

The prevalence of samples with one or more benzodiazepines detected ranged from $40 \%$ in 2000 to $63 \%$ in 2002. After 2002 the prevalence detected has varied between 52 and $57 \%$ among all apprehended driver samples. Flunitrazepam was the most prevalent benzodiazepine until 2003. From 2003 to 2009 the prevalence of flunitrazepam decreased, while the prevalence of alprazolam, diazepam and in particular clonazepam increased (Table 1). Samples with more than one benzodiazepine increased significantly from year 2000 to 2009 (Table 1). Two thirds of all drivers who were found to be positive for amphetamine or methamphetamine were also positive for one or more benzodiazepine.

\section{Seizures compared to blood sample findings}

Flunitrazepam was the most prevalent benzodiazepine in both seizures (7) and among apprehended drivers in 2002 , representing about $70 \%$ in both types of cases. Both seizures (7) and analytical results of blood samples from apprehended drivers show a marked flunitrazepam decrease from 2002 to 2005 (Figure 2). During the same period, both seizures (7) and analytical re- 
Table 1. Prevalence of amphetamines and benzodiazepines in blood samples from apprehended drivers.

\begin{tabular}{|c|c|c|c|c|c|c|c|c|c|c|c|c|}
\hline & $\begin{array}{c}\text { Year } \\
\mathrm{n}\end{array}$ & $\begin{array}{l}2000 \\
3507\end{array}$ & $\begin{array}{l}2001 \\
3974\end{array}$ & $\begin{array}{l}2002 \\
4812\end{array}$ & $\begin{array}{l}2003 \\
4016\end{array}$ & $\begin{array}{l}2004 \\
3705\end{array}$ & $\begin{array}{l}2005 \\
3729\end{array}$ & $\begin{array}{l}2006 \\
3916\end{array}$ & $\begin{array}{l}2007 \\
3951\end{array}$ & $\begin{array}{l}2008 \\
4113\end{array}$ & $\begin{array}{l}2009 \\
4212\end{array}$ & $\begin{array}{c}\text { Substance by year }{ }^{1} \\
\text { OR }(95 \% \text { CI })\end{array}$ \\
\hline Amphetamines \% & & 35 & 40 & 43 & 40 & 39 & 39 & 40 & 37 & 38 & 40 & $1.00(0.99-1.01)^{(\mathrm{ns})}$ \\
\hline Amphetamine \% & & 34 & 38 & 40 & 38 & 35 & 36 & 34 & 29 & 28 & 26 & $0.94(0.94-0.95) * *$ \\
\hline $\begin{array}{l}\text { Amphetamine } \% \text {-no } \\
\text { meth finding }\end{array}$ & & 32 & 31 & 32 & 29 & 26 & 25 & 20 & 15 & 12 & 5 & $0.83(0.83-0.84)^{* *}$ \\
\hline Methamphetamine $\%$ & & 3 & 8 & 11 & 11 & 13 & 14 & 21 & 23 & 26 & 35 & $1.27(1.25-1.28)^{* *}$ \\
\hline Benzodiazepines \% & & 40 & 53 & 63 & 54 & 56 & 56 & 57 & 55 & 52 & 53 & $1.02(1.01-1.02)^{* *}$ \\
\hline Flunitrazepam & & 18 & 31 & 43 & 21 & 18 & 12 & 7 & 9 & 5 & 2 & $0.76(0.75-0.77)^{* *}$ \\
\hline Clonazepam & & 6 & 7 & 7 & 13 & 14 & 15 & 12 & 14 & 17 & 21 & $1.15(1.14-1.16)^{* *}$ \\
\hline Alprazolam & & 1 & 2 & 2 & 4 & 10 & 7 & 6 & 5 & 7 & 10 & $1.18(1.16-1.20)^{* *}$ \\
\hline Diazepam & & 19 & 22 & 23 & 21 & 21 & 26 & 36 & 32 & 29 & 26 & $1.07(1.06-1.07)^{* *}$ \\
\hline Oxazepam & & 1 & 3 & 4 & 5 & 6 & 6 & 6 & 6 & 6 & 6 & $1.11(1.09-1.13)^{* *}$ \\
\hline Nitrazepam & & 1 & 2 & 3 & 7 & 6 & 12 & 9 & 9 & 8 & 6 & $1.13(1.11-1.15)^{* *}$ \\
\hline \multirow[t]{3}{*}{$\begin{array}{l}\text { \# of positive } \\
\text { benzodiazepines }\end{array}$} & $n^{2}$ & 1397 & 2095 & 3015 & 2153 & 2059 & 2088 & 2246 & 2173 & 2137 & 2231 & \\
\hline & 1 & 54 & 55 & 57 & 50 & 50 & 43 & 33 & 36 & 37 & 42 & \\
\hline & $\geq 2$ & 46 & 45 & 43 & 50 & 50 & 57 & 67 & 64 & 63 & 58 & $1.11(1.09-1.12)^{* *}$ \\
\hline
\end{tabular}

${ }^{1}$ Logistic regression analysis of substance present or not by year, test of statistic significance: (ns): not statistically significant, $* * \mathrm{p}<=0.001$

${ }^{2}$ Among apprehended drivers positive for benzodiazepines

sults in blood samples of all other benzodiazepines increased. The highest increase was observed for clonazepam; in $20024 \%$ of the benzodiazepine seizures and $12 \%$ of the benzodiazepine findings were clonazepam, increasing to $28 \%$ and $40 \%$ respectively, in 2009 (Figure 2). Methamphetamine in seizures (7) and apprehended drivers represented less than $10 \%$ in both types of cases in 2000. In 2009 the proportion of methamphetamine was more than $60 \%$ of the seized amphetamines (7). The proportion of methamphetamine detected among apprehended drivers represented about $90 \%$ of all the amphetamine/methamphetamine cases in 2009 (Figure 3).
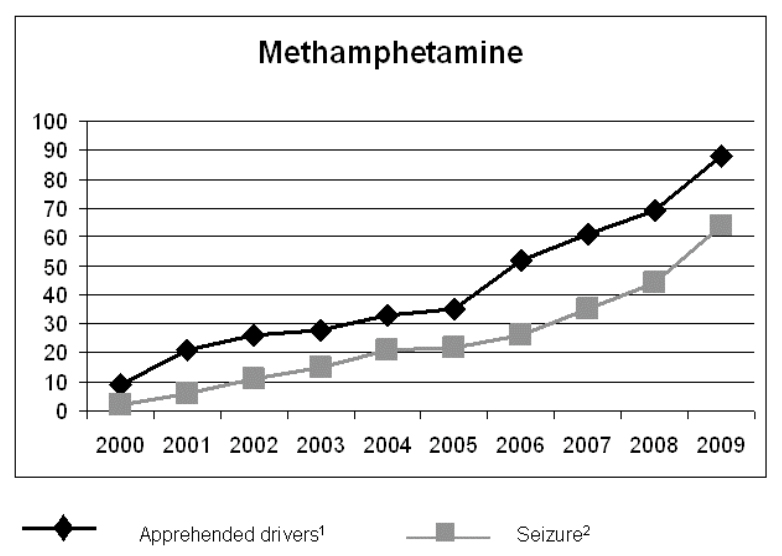

Figure 3. Prevalence of methamphetamine in amphetamine blood sample findings and police seizures by year (Data from police seizures derives from Drugs and doping statistics $2010(7))$.

${ }^{1}$ Proportion of methamphetamine among drivers screening positive for amphetamines

${ }^{2}$ Proportion of methamphetamine in all seizures of amphetamine and methamphetamine

\section{DISCUSSION}

After 2002 the prevalence of benzodiazepine has ranged from $52-57 \%$ among all apprehended drivers. There have been major changes in single substance prevalence, and these changes are similar to the changes in benzodiazepines seized by the police. There have been minor changes in the prevalence of amphetamines totally from 2000 to 2009 , but the most prevalent stimulant has shifted from amphetamine to methamphetamine in both police seizures and blood samples from apprehended drivers.

\section{Strengths and limitations}

The major strengths were the size of the study population of all drivers apprehended from the whole country, and the long time period covered by the dataset. Another major strength was that all samples from suspected drug drivers in Norway has been analysed in one laboratory at NIPH.

A minor weakness was that there have been some changes in analytic methods and analytic cut-off level concentrations for benzodiazepines in the beginning of the study period. However, according to the high concentration levels for benzodiazepines detected the changes of cut-off levels seem to have had minor effects of the results presented in this study. It would have strengthened the study to calculate the amphetamine to methamphetamine ratio in drivers positive for both. This would have made it possible to distinguish between combined use of amphetamine and methamphetamine and methamphetamine use alone. The samples of this study were ordered by the police on suspicion of impairment of drugs other than alcohol. The drivers have therefore undergone evaluation with regard to possible driving under the influence of non-alcohol 
drugs, before blood samples were taken for documentation of possible drug impairment. The majority of samples were therefore positive and the prevalence rate not possible to generalize to any other population.

\section{Interpretation}

\section{Amphetamine and methamphetamine}

As hypothesised, prevalence rate for amphetamines (amphetamine or methamphetamine) did not change significantly between 2000 and 2009. However, the most prevalent amphetamine shifted from amphetamine to methamphetamine. As methamphetamine metabolizes to amphetamine, finding of amphetamine together with methamphetamine may be from ingestion of methamphetamine alone. The results indicate that the majority of apprehended drivers with amphetamine detected used methamphetamine, either in combination with amphetamine or alone. Widespread use of methamphetamine has not been common in Europe (13). It has traditionally been used in the former Czechoslovakia, while amphetamine use has been more common in north east and central Europe (14). Amphetamines were the most prevalent illicit drugs among apprehended drivers in both Sweden and Finland, however no distinction was made between amphetamine and methamphetamine in these studies $(15,16)$. A shift from amphetamine to methamphetamine has been reported in some Scandinavian and Baltic countries, in line with the findings of this study (14). In 2010 The European Monitoring Centre for Drugs and Drug Addiction (EMCDDA) reported increasing seizures of methamphetamine from 2003, especially in Norway (17). In a recent study of injured patients admitted to hospital in Norway methamphetamine was detected in about $80 \%$ of the patient samples positive for amphetamines (18). Studies of the general Norwegian population found lifetime prevalence for amphetamines use of about $4 \%$. Last year use was below $1 \%$, the survey does not distinguish between amphetamine and methamphetamine (19). Trends in use among apprehended drivers may be a supplement to such reports as it gives a more detailed knowledge of the drug situation in groups who use drugs, and emerging trends may be detected earlier, as the samples does not rely on the respondents knowledge of substance ingested. As hypothesised, there was a match between the development in methamphetamine seizures and prevalence among apprehended drivers. This strengthens the assumption that there has been a shift from amphetamine to methamphetamine use among Norwegian drug abusers. The findings in this population can not be generalized to Norwegian problem drug users in general although they may be represented in the sample.

\section{Benzodiazepines}

In contrast to our hypothesis, the total prevalence of benzodiazepine findings among apprehended drivers fluctuated significantly. In 2002 about $60 \%$ of the apprehended drivers were found positive for benzodiazepines and the most prevalent substance was flunitrazepam. Although the presence of flunitrazepam has declined significantly since 2002 , the total prevalence of benzodiazepines was still over $50 \%$ during the whole period after 2002, because other substances have replaced flunitrazepam. The finding of more than one benzodiazepine has showed an increasing trend, especially after 2005 . A Norwegian study found demographic differences between users of prescribed benzodiazepines and apprehended drivers tested positive for benzodiazepines (3). Studies of apprehended drivers from countries outside Scandinavia found a lower prevalence of benzodiazepines varying from $4 \%$ in Ireland (20) and Hungary (21) to 6\% in Switzerland (22). A study from Finland found benzodiazepines as the most prevalent drug group (76\%) in a study of all apprehended drivers from 1977 to 2001 (16). Benzodiazepines was the second most prevalent substance group in apprehended drivers from 1997 to 2008 in Denmark (29-55\%) (23). As hypothesised it was a similarity in rise and decline in police seizures and prevalence among apprehended drivers. The similarity between the two samples together with a high prevalence of combined use, suggests use of non prescribed and illegally bought benzodiazepines. Another support to the assumption was intake above recommended therapeutic doses, reported by another study of Norwegian apprehended drivers (3). Therefore restrictions on prescription status of benzodiazepines may not have the same effect as it has had for other groups of drug users $(24,25)$.

\section{Conclusion}

Drug prevalence in apprehended drivers matched the police seizures and gave a good indication of trends in amphetamine and illegal benzodiazepine use. A combination of benzodiazepines and amphetamines was commonly detected in apprehended drivers. Interventions to reduce drug use and other preventive measures should be considered for drivers combining drugs with driving, as they constitute a great risk for themselves and other road-users.

\section{REFERENCES}

1. Christophersen AS, Skurtveit S, Grung M, Mørland J. Rearrest rates among Norwegian drugged drivers compared with drunken drivers. Drug Alcohol Depend 2002; 66: 85-92.

2. Christophersen AS, Skurtveit S, Mørland J. [Impaired driving as an indicator of drug abuse: what consequences for treatment?]. Tidsskr Nor Laegeforen 2003; 123: 1841-3. 
3. Christophersen AS, Mørland J. Frequent detection of benzodiazepines in drugged drivers in Norway. Traffic Inj Prev 2008; 9: 98-104.

4. Christophersen AS, Mørland J. Drugged driving, a review based on the experience in Norway. Drug Alcohol Depend 1997; 47: 125-35.

5. Khiabani HZ, Christophersen AS, Morland J. [Routines upon suspicion of driving under influence]. Tidsskr Nor Laegeforen 2007; 127: 618-9.

6. Hausken AM, Skurtveit S, Christophersen AS. Mortality among subjects previously apprehended for driving under the influence of traffic-hazardous medicinal drugs. Drug Alcohol Depend 2005; 79: 423-9.

7. KRIPOS. Narkotika og dopingstatistikk 2010. 2010.

8. Baselt RC. Disposition of toxic drugs and chemicals in man, 8th edn. Foster City, CA: Biomedical Publications, 2008.

9. Christophersen AS, Gulliksen M, Hasvold I, Johansen U, Karinen R, Ripel A, et al. Screening, confirmation and quantification of drugs of abuse in whole blood by LC- MS (ESI). In: Abstracts of The 39th Meeting of The International Association of Forensic Toxicologists (TIAFT). Prague, 2001.

10. Øiestad EL, Johansen U, Øiestad AM, Christophersen AS. Drug screening of whole blood by ultraperformance liquid chromatography-tandem mass spectrometry. J Anal Toxicol 2011; 35: 280-93.

11. Gjerde H, Christophersen AS, Skuterud B, Klemetsen K, Mørland J. Screening for drugs in forensic blood samples using EMIT urine assays. Forensic Sci Int 1990; 44: 179-85.

12. Gjerde H, Hasvold I, Pettersen G, Christophersen AS. Determination of amphetamine and methamphetamine in blood by derivatization with perfluorooctanoyl chloride and gas chromatography/mass spectrometry. J Anal Toxicol 1993; 17: 65-8.

13. Griffiths P, Mravcik V, Lopez D, Klempova D. Quite a lot of smoke but very limited fire - the use of methamphetamine in Europe. Drug Alcohol Rev 2008; 27: 236-42.

14. EMCDDA. Problem amphetamine and methamphetamine use in Europe. Luxembourg: Publications Office of the European Union, 2010.

15. Holmgren A, Holmgren P, Kugelberg FC, Jones AW, Ahlner J. Predominance of illicit drugs and poly-drug use among drug-impaired drivers in Sweden. Traffic Inj Prev 2007; 8: 361-7.

16. Ojaniemi KK, Lintonen TP, Impinen AO, Lillsunde PM, Ostamo AI. Trends in driving under the influence of drugs: a register-based study of DUID suspects during 1977-2007. Accid Anal Prev 2009; 41: 191-6.

17. EMCDDA. 2010 Annual report on the state of the drugs problem in Europe. Lisbon: EMCDDA, 2010.

18. Bogstrand ST, Normann PT, Rossow I, Larsen M, Mørland J, Ekeberg Ø. Prevalence of alcohol and other substances of abuse among injured patients in a Norwegian emergency department. Drug Alcohol Depend 2011; 117: 132-8.

19. Hordvin O. The Drug Situation in Norway 2010. Oslo: SIRUS, 2010.

20. Fitzpatrick P, Daly L, Leavy CP, Cusack DA. Drinking, drugs and driving in Ireland: more evidence for action. Inj Prev 2006; 12: 404-8.

21. Toth AR, Varga T, Molnar A, Hideg Z, Somogyi G. The role of licit and illicit drugs in traffic (Hungary 2000-2007). Leg Med (Tokyo) 2009; 11 Suppl 1: S419-22.

22. Senna MC, Augsburger M, Aebi B, Briellmann TA, Donze N, Dubugnon JL, et al. First nationwide study on driving under the influence of drugs in Switzerland. Forensic Sci Int 2010; 198: 11-6.

23. Steentoft A, Simonsen KW, Linnet K. The frequency of drugs among Danish drivers before and after the introduction of fixed concentration limits. Traffic Inj Prev 2010; 11: 329-33.

24. Ekeberg Ø, Jacobsen D, Flaaten B, Mack A. Effect of regulatory withdrawal of drugs and prescription recommendations on the pattern of self-poisonings in Oslo. Acta Med Scand 1987; 221: 483-7.

25. Bramness JG, Skurtveit S, Furu K, Engeland A, Sakshaug S, Rønning M. [Changes in the sale and use of flunitrazepam in Norway after 1999]. Tidsskr Nor Laegeforen 2006; 126: 589-90. 